Tropical Journal of Pharmaceutical Research March 2017; 16 (3): 697-704

ISSN: $1596-5996$ (print); 1596-9827 (electronic)

(C) Pharmacotherapy Group, Faculty of Pharmacy, University of Benin, Benin City, 300001 Nigeria.

All rights reserved.

Available online at http://www.tjpr.org

Original Research Article

http://dx.doi.org/10.4314/tjpr.v16i3.27

\title{
Evaluation of drug therapy problems among renal patients receiving care in some tertiary hospitals in Nigeria
}

\author{
Maxwell O Adibe*, Nneka U Igboeli and Chinwe V Ukwe \\ Pharmacotherapeutic Group and Department of Clinical Pharmacy and Pharmacy Management, University of Nigeria, Nsukka, \\ Nigeria
}

*For correspondence: Email: Maxwell.adibe@unn.edu.ng, maxolpharmacia@yahoo.com; Tel: +2348037781479

Revised accepted: 8 July 2016

\begin{abstract}
Purpose: To determine the prevalence of drug therapy problems (DTPS), identify the types of DTPs and assess outcomes of DTP interventions among renal patients receiving care in three Nigerian tertiary hospitals.

Methods: This prospective descriptive study was conducted in nephrology units of three tertiary hospitals in Nigeria, based on recommendations of working conference of the Pharmaceutical Care Network Europe, version 6.2 while the reviews, classification of DTPs and principles of drug use in chronic kidney diseases (CKD) were based on evidence-based clinical guidelines and standards of practice (Kidney Disease: Improving Global Outcomes (KDIGO).

Results: Out of 234 DTPs identified, 90 (38.46\%) had drug choice problem, 86 (36.75\%), had problems of drug interactions; 47(20.09\%), had dosing problem, while 11 (4.70\%) had drug use problem. Clinical interventions (459) were undertaken at prescriber level (78; 16.99\%); patient/carer level (211, $46.00 \%)$ and drug level (170, $30.04 \%)$. Pharmacists recommended 376 of the interventions for approval, out of which 310 (67.54\%) were approved. Amongst the DTPs indentified, $47.86 \%$ were successfully resolved.

Conclusion: Drug therapy problems among renal patients were high. Inappropriate drug selection and drug interactions were the commonest drug therapy problems. The acceptance of pharmacists' interventions by prescribers was appreciable.
\end{abstract}

Keywords: Drug therapy problems, Renal patients, Therapy, Intervention, Outcomes

Tropical Journal of Pharmaceutical Research is indexed by Science Citation Index (SciSearch), Scopus, International Pharmaceutical Abstract, Chemical Abstracts, Embase, Index Copernicus, EBSCO, African Index Medicus, JournalSeek, Journal Citation Reports/Science Edition, Directory of Open Access Journals (DOAJ), African Journal Online, Bioline International, Open-J-Gate and Pharmacy Abstracts

\section{INTRODUCTION}

Medications intended for the treatment, prophylaxis or diagnosis of medical conditions may have negative effects on patients if not used appropriately. Over the years, there have been numerous reports of incidence, prevalence, and preventability of drug-related hospital admissions [1-3], medication error-related deaths [4], and adverse drug events in in-patient and out-patient settings [5-7]. Drug-related problems are common in hospitalized patients and can interfere with the achievements of desired therapeutic outcomes [8]. These problems can potentially have an impact on desired health outcomes [9]. Due to their training, pharmacists can play an important role in identifying these drug therapy problems (DTPs), resolving actual DTPs and preventing potential DTPs through careful pharmaceutical practices. There is increasing evidence that participation and interventions of clinical pharmacists in health care have a positive influence on clinical practice [10]. In a number of studies, clinical pharmacists have been shown to reduce DRPs in the in- 
patient settings [11]. Some publications have evaluated the impact of drug errors identified or intercepted by pharmacists in emergency departments [12-14], and in in-patient medical and surgical wards $[15,16]$.

In CKD, the number and complexity of drugs increase with the progression of the disease and can result in a high risk of non-compliance and adverse drug reactions. Moreover, CKD patients are more at risk of iatrogenic renal failure than non-CKD patients $(15.3 \%$ vs. $5.3 \%$, respectively) when admitted to an intensive care unit [17]. Several studies have shown that patients with end-stage renal disease (ESRD) are among those at high risk for DTPs $[18,19]$.

The objectives of this study were to determine the prevalence of DTPs, identify the types of DTPs, and assess the outcomes of DTP interventions among renal patients receiving care in three Nigerian tertiary hospitals.

\section{METHODS}

\section{Study design and setting}

This prospective descriptive study was conducted in nephrology unit of University of Nigeria Teaching Hospital (UNTH), Enugu; Nnamdi Azikiwe Teaching Hospital, Nnewi and Enugu State University Teaching Hospital. These are tertiary hospitals that serve as referral centres to most of the hospitals, in particular, in South-Eastern geo-political zone of Nigeria. Ethical clearance of the study was obtained from each hospital ethics committee prior to data collection.

\section{Study participants}

The study included all renal patients who were diagnosed with acute renal failure, chronic renal failure and other kidney related diseases; 18 years and above, with or without co-morbidities, and on admission to the medical ward for kidneyrelated problems from October, 2014 to March, 2015.

\section{Instruments for study}

This study protocol was based on the recommendation made during the working conference of the Pharmaceutical Care Network Europe, a classification scheme constructed for drug related problems (DRPs, V6.2) [20].

The questionnaire used in this study had information on the patient's demographic characteristics, including age, sex, and medical history, drugs administered to the patient during the hospitalization period: Drug name, indication, dose, schedule, duration, and monitoring, stage of CKD, associated co-morbidities, length of hospital stay, and number of drugs prescribed, and the type of DRPs and pharmacist's interventions.

\section{Data collection}

Identification and classification of potential and actual DRPs using appropriate guidelines was assessed by 3 clinical pharmacists through review and analyses of all medication orders, administration sheets, laboratory and diagnostic test results and pathophysiological status. Patients were interviewed for relevant information for the study. The reviews, classification of DTPs and principles of drug use in the CKD were based on evidence-based clinical guidelines and standards of practice $[21,22]$. These guidelines have sections for use of drug in patients with CKD in reference to other co-morbidities, CKD progression/staging and dosage adjustment charts and DTPs in CKD for individual drugs or groups of drugs.

Drug-drug interactions were assessed using RxList drug interaction platform [23]. The RxList identifies how the number of interactions in a prescription and rates them into the following categories:

a) Contra-indicated: Never use this combination of drugs because of high risk for dangerous interaction

b) Serious: Potential for serious interaction; regular monitoring by your doctor required or alternative medication may be needed

c) Significant: Potential for significant interaction (monitoring by your doctor is likely required)

d) Minor: Interaction is unlikely, minor, or nonsignificant

Each patient's drug therapy was routinely monitored in every follow-up appointment and the DRPs were identified, discussed, and documented by the panel. The DTPs and other medical related matters were unanimously agreed upon during a round table discussion by panel members (differences were resolved by consensus). Intervention involved discussion of resolution of the problem with the prescribers, counselling and educating the patients as appropriate and change or discontinuation of the drug. Drug therapeutic problem charts were collected, analyzed, and categorized into types of problems, causes of problems, interventions, and outcomes of interventions. The medication 
therapy review was tailored to the individual problems of the patient at each encounter. Following identification of any DTPs, an intervention was proposed to the patient, or the physician or other healthcare professionals, or both, as appropriate so as to optimize therapy. The communication of appropriate information to the physician or other healthcare professional including consultation on the selection of medications, correct dosage regimens, suggestions to address medication problems, recommendations and outcomes were documented.

\section{Data analysis}

The data were collated and entered into version 21 of SPSS (SPSS Inc. Chicago) and Microsoft 2007 Excel package for analysis. Descriptive statistics was done and continuous variables were expressed as means \pm standard deviation.

\section{RESULTS}

\section{Patients socio-demographic characteristics}

A total of 287 patients with renal illnesses were followed for five months and assessed for DTPS. More than half of the patients were above 50 years old $(165,57.49 \%)$, out of which 171 (59.58 $\%$ ) were female. Majority of patients were married $(239,83.28 \%)$ and about one third of them earned less than $\$ 18,000$ monthly (Table $1)$.

\section{Patients' clinical variables}

The clinical features of the patients showed that mean serum creatinine, Glomerular Fitration Rate (GFR) and hospital stay were $1.34 \pm 0.32$ $\mathrm{mg} / \mathrm{dl}, 52.55 \pm 14.31 \mathrm{ml} / \mathrm{min} / 1.73 \mathrm{~m}^{2}$ and $16.24 \pm$ 4.26 days, respectively. The number of patients with CKD stages G3 to 5, was 208 (72.48 \%). A total of 484 co-morbidities (mean: $1.69 \pm 0.12$ ) were documented, with hypertension and diabetes accounting for about two-thirds of the co-morbid conditions. Most of the patients (197, $68.64 \%$ ) had 2 or 3 co-morbid conditions (Table 2).

The total number of drugs received by patients was 831 and the number of drugs in the prescriptions of most patients $(52.96 \%)$ ranged from 3 to 5 with an average of $2.90 \pm 1.03$ per patient. The number of drugs with restriction in renal impairment $(\mathrm{RI})$ was 209 , with an average of $0.73 \pm 0.13$ drugs per patient (Table 3 ).

Amongst the 201 patients with DTPs, 234 DTPs were identified in following descending order of their prevalence 'drug choice problem': 90 (38.46 $\%)$; 'drug interactions': 86 (36.75 \%); 'dosing problem' 47 (20.09\%); drug use problem: 11 (4.70\%) and adverse drug reaction: 0 (0.00\%). The detailed results showed that top specific causes of DTPs were "potential drug interactions $(36.75 \%)$ and 'drug dose too high or dosage regime too frequent' (Table 4 ).

Table 1: Patients socio-demographic characteristics

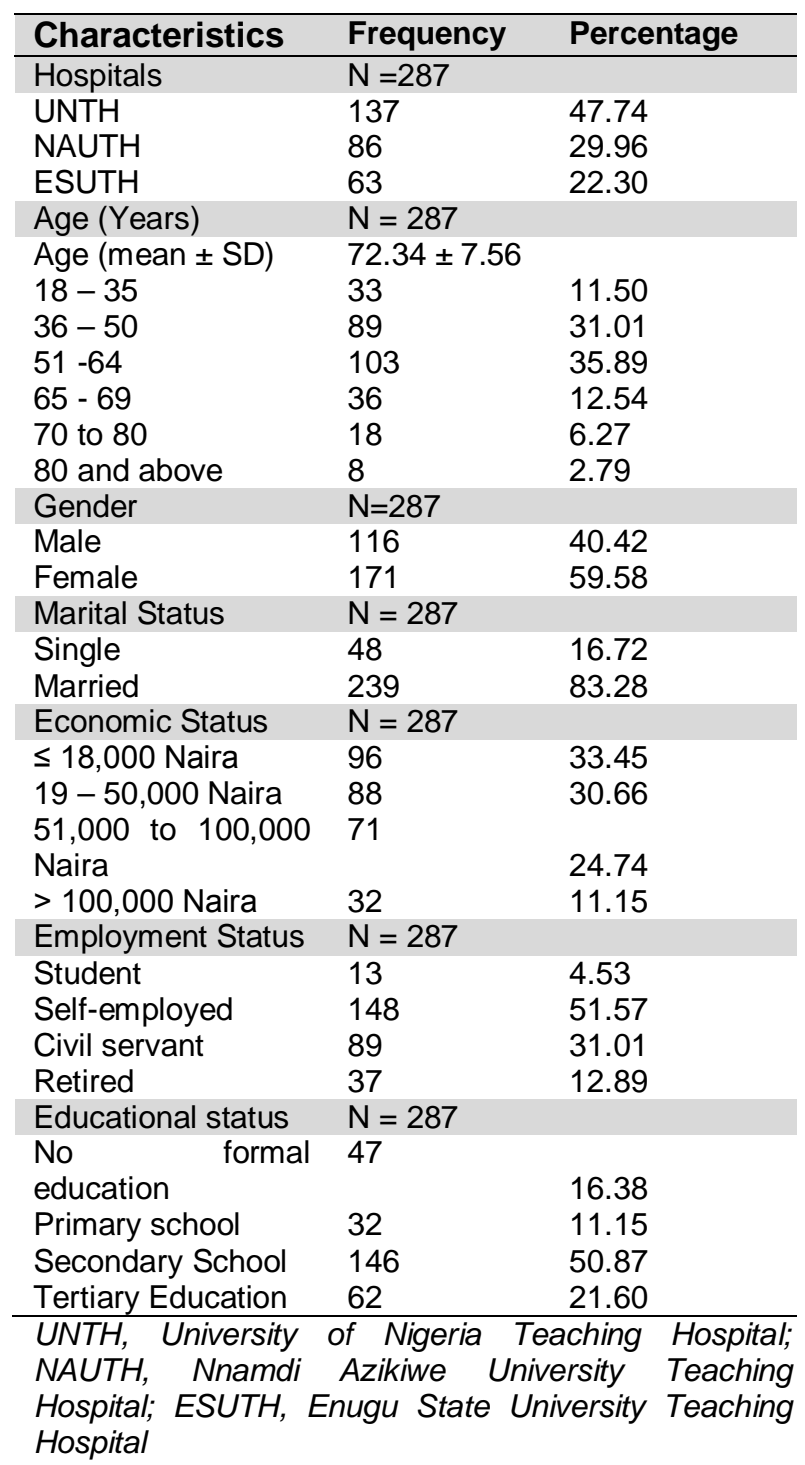

A total of 459 clinical interventions were undertaken at three levels of the intervention: prescriber level: 78 (16.99\%); patient/career level: 211 (46.00\%) and drug level: 170 $(30.04 \%)$. Out these, 'prescriber informed only' (47, $60.26 \%)$, 'patient (medication) counselling' $(111,52.61 \%)$ and 'dosage changed' (84, 49.41 $\%$ ) were the most recommended for intervention at each level. Out of the 459 interventions, 376 $(81.91 \%)$ were recommended for approval from the prescribers, out of which 310 (67.54\%) were approved (Table 5). 
Of the 234 DTPs identified, 'problems totally solved' was 112 (47.86 \%), 'partially solved' was 42 (17.95\%), 'problem not solved due to lack of cooperation of the patient' was 12 (5.13\%), 'problem not solved due to lack of cooperation of prescriber' was $36(15.38 \%)$ and 'outcomes not known' was 32 (13.68\%), Table 5.

Table 2: Patient clinical characteristics

\begin{tabular}{|c|c|}
\hline Variables & Mean \pm SD \\
\hline Weight (kg) & $64.21 \pm 13.45$ \\
\hline Height $(\mathrm{m})$ & $1.52 \pm 0.23$ \\
\hline $\mathrm{BMI}\left(\mathrm{Kg} / \mathrm{m}^{2}\right)$ & 26. $76 \pm 2.44$ \\
\hline $\mathrm{SBP}(\mathrm{mm} \mathrm{Hg})$ & $138.67 \pm 8.32$ \\
\hline $\mathrm{DBP}(\mathrm{mm} \mathrm{Hg})$ & $87.23 \pm 7.65$ \\
\hline Creatinine (mg/dl) & $1.34 \pm 0.32$ \\
\hline GFR $\left(\mathrm{ml} / \mathrm{min} / 1.73 \mathrm{~m}^{2}\right)$ & $52.55 \pm 14.31$ \\
\hline Mean Hospital stay (days) & $16.24 \pm 4.26$ \\
\hline CKD Stage & n (\%) \\
\hline G1 & $29(10.10)$ \\
\hline G2 & $50(17.42)$ \\
\hline G3a & $131(45.64)$ \\
\hline G3b & $44(15.33)$ \\
\hline G4 & $21(7.32)$ \\
\hline G5 & $12(4.18)$ \\
\hline${ }^{*}$ Co-morbidity $\quad(n=484)$ & $\mathrm{n}(\%)$ \\
\hline Diabetes & $156(32.23)$ \\
\hline Hypertension & $203(41.94)$ \\
\hline $\mathrm{CHF}$ & $32(6.61)$ \\
\hline Dyslipidemia & $43(8.88)$ \\
\hline Hypo/Hyper Thyrodism & $9(1.86)$ \\
\hline Anemia & $16(3.31)$ \\
\hline $\begin{array}{l}\text { Chronic obstructive-pulmonary } \\
\text { disease }\end{array}$ & $13(2.69)$ \\
\hline Others & $12(2.48)$ \\
\hline *Total number of co-morbidity & 484 \\
\hline $\begin{array}{l}\text { Average number of } \\
\text { comorbidity per patient (Mean } \\
\pm \text { SD) }\end{array}$ & $1.69 \pm 0.12$ \\
\hline $\begin{array}{l}\text { Number of co-morbid } \\
\text { conditions }\end{array}$ & $\mathrm{n}(\%)$ \\
\hline 0 or 1 & $62(21.60)$ \\
\hline 2 or 3 & $197(68.64)$ \\
\hline 4 and above & $28(9.79)$ \\
\hline \multicolumn{2}{|l|}{ Haemodialysis } \\
\hline Yes & $8(2.79)$ \\
\hline No & 279 (97.21) \\
\hline
\end{tabular}

*Some patients had more than one comorbidity. Abbreviations: $B M I=$ Body Mass Index, $S B P=$ systolic blood pressure, $D B P=$ diastolic blood pressure; GFR = glomerular filtration rate

\section{DISCUSSION}

This study has revealed a very high proportion (70.03\%) of CKD patients with DRPs. Out of the $67.54 \%$ of interventions by pharmacist approved by a panel, $47.86 \%$ of the DTPs identified were successfully resolved. This high proportion of DTPs might be due to relatively older population involved in the study, as well as severe CKD and multiple co-morbidities among the renal patients.

Increasing age causes increasing vulnerability to diseases and, in the elderly, the tendency to acquire multiple and chronic diseases. This population therefore is prescribed and uses more drugs than younger populations. In addition, multiple complaints, atypical disease presentation and physician prescribing habits and practices have resulted in the use of multiple drugs by these patients [24]. Age is one of the most important underlying risk factors for CKD, often compounded by the presence of other comorbidities such as diabetes, hypertension and vascular disease. Among healthy individuals, creatinine clearance peaks at approximately 120 $130 \mathrm{~mL} / \mathrm{min} / 1.73 \mathrm{~m}^{2}$ at age 30 years and then declines by about $8 \mathrm{~mL} / \mathrm{min} / 1.73 \mathrm{~m}^{2}$ per decade [21].This result is in agreement with the findings in an earlier study [25], which showed that majority of patients with DTP were 60 years and above.

Most of the patients in this study had CKD stage 3-5 which requires a therapeutic intensification to slow the progression of the disease, prevent risk of acute kidney injury and treat co-morbidities, particularly cardiovascular risk factors [26]. In doing these, there is need to pay close attention on the GFR of the patients, to make sure the CKD stage does not go beyond G2: this study had shown a significant likelihood of increase in the number of DTPs by 6.52 for every additional deteriorating stage, provided the patients are of the same in other variables.

More than one-quarter of the patients had at least 4 co-morbidities and about two-thirds received at least 3 medications. While no specific number of medications has been established to define polypharmacy, some have arbitrarily suggested cut-off points of 3 to 5 drugs per patient [27]. Our results appear to conform with this, since $14.63 \%$ of the patients received 6 or more drugs. In addition, the patients included in this investigation had several risk factors for polypharmacy, including older age, renal disorders, and poorer health [27].

This revelation underscores the need for extra vigilance while reviewing patient's drugs as this could increase their DTPs and cost. A total of 234 drug therapy problems (DTPs) were identified which resulted from drugs prescribed during the study. This is considered high. Although Ramalho de Oliveira et al. [28] identified 38,631 DTPs over a period of 10 years, 
Table 3: Prescription parameters

\begin{tabular}{|c|c|}
\hline Prescription parameter & $\mathrm{n}, \mathrm{n}(\%)$, Mean \pm SD \\
\hline${ }^{\star}$ Total number of drugs prescribed (n) & 831 \\
\hline Average number of drugs per patient (Mean \pm SD) & $2.90 \pm 1.03$ \\
\hline Number of drugs per patient $\quad n(\%)$ & $\mathrm{n}=\mathbf{2 8 7}$ \\
\hline $0-2$ & $93(32.40)$ \\
\hline 3 to 5 & $152(52.96)$ \\
\hline 6 and above & $42(14.63)$ \\
\hline${ }^{*}$ Total number of drugs with restriction in renal impairment encountered (n) & 209 \\
\hline Drugs with restriction in $\mathrm{RI}$ per patient (Mean \pm SD) & $0.73 \pm 0.13$ \\
\hline Total number DTPs encountered $(n)$ & 234 \\
\hline !Total number of patients with DTPs $\mathrm{n}(\%)$ & $201(70.03)$ \\
\hline Average number of DTPS per patient (Mean \pm SD) & $0.84 \pm 0.08$ \\
\hline Number of DTPs per patient $\mathbf{n}(\%)$ & $n=287$ \\
\hline 0 & $53(18.47)$ \\
\hline 1 or 2 & $172(59.93)$ \\
\hline More than 2 & $62(21.60)$ \\
\hline${ }^{\circ}$ Prevalence of drug interactions $\mathrm{n}(\%)$ & $86(36.75)$ \\
\hline RxList Categories of Drug interactions $n(\%)$ & $\mathrm{n}=86$ \\
\hline Contra-indicated & $38(44.19)$ \\
\hline Serious & $23(26.74)$ \\
\hline Significant & $8(9.30)$ \\
\hline Minor & $17(19.77)$ \\
\hline Interventions $\mathbf{n}(\%)$ & $n=459$ \\
\hline Intervention proposed, approved by prescriber & $310(67.54)$ \\
\hline Intervention proposed, not approved by prescriber & $66(14.38)$ \\
\hline Interventions not proposed for approval by prescriber & $83(18.08)$ \\
\hline
\end{tabular}

*Some drug appeared severally: ! potential and actual DTPs; ${ }^{\circ}$ The denominator was 234 (total DTPs encountered); RI = renal impairment, DTP = Drug-Therapy problem, DI = Dosing inadequacy, Drugs with restrictions (dose adjustment needed in case of renal impairment $(\mathrm{RI})$ ) per patient, $\mathrm{SD}=$ Standard deviation.

Table 4: Drug therapy problems

\begin{tabular}{|c|c|c|}
\hline Identified drug therapy problem & Freqency & Percentage \\
\hline \multicolumn{3}{|l|}{ Adverse reactions (Patient suffers from an adverse drug event) } \\
\hline Side effect suffered (non-allergic) & 0 & 0.00 \\
\hline Side effect suffered (allergic) & 0 & 0.00 \\
\hline Toxic effects suffered & 0 & 0.00 \\
\hline \multicolumn{3}{|l|}{$\begin{array}{l}\text { Drug choice problem (Patient gets or is going to get a wrong (or no drug) drug } \\
\text { for his/her disease and/or condition) }\end{array}$} \\
\hline Inappropriate drug (not most appropriate for indication) & 9 & 3.85 \\
\hline Drug treatment more costly than necessary & 15 & 6.41 \\
\hline Inappropriate drug form (not most appropriate for indication) & 7 & 2.99 \\
\hline Inappropriate duplication of therapeutic group or active ingredient & 18 & 7.69 \\
\hline $\begin{array}{l}\text { Contra-indication for drug (including pregnancy/breast feeding, Renal } \\
\text { impairment) }\end{array}$ & 28 & 11.97 \\
\hline No clear indication for drug use & 6 & 2.56 \\
\hline No drug prescribed but clear indication & 7 & 2.99 \\
\hline \multicolumn{3}{|l|}{$\begin{array}{l}\text { Dosing problem (patient gets more or less than the amount of drug he/she } \\
\text { requires) }\end{array}$} \\
\hline $\begin{array}{l}\text { Drug dose too low or dosage regime not frequent enough } \\
\text { Drug dose too high or dosage regime too frequent (need dose adjustment }\end{array}$ & 9 & 3.85 \\
\hline according to CKD stage) & 31 & 13.25 \\
\hline Duration of treatment too short & 3 & 1.28 \\
\hline Duration of treatment too long & 4 & 1.71 \\
\hline \multicolumn{3}{|l|}{ Drug use problem (wrong or no drug taken/ administered) } \\
\hline Drug not taken/administered at all & 11 & 4.70 \\
\hline Wrong drug taken/administered & 0 & 0.00 \\
\hline \multicolumn{3}{|l|}{ Interactions (manifest or potential drug-drug or drug-food interaction) } \\
\hline Potential interaction & 86 & 36.75 \\
\hline Manifest interaction & 0 & 0.00 \\
\hline Therapy failure (reason unknown) & 0 & 0.00 \\
\hline
\end{tabular}


Table 5: The DTPs Interventions and Outcomes

\begin{tabular}{|c|c|c|c|}
\hline${ }^{*}$ Interventions & & Frequency & Percentage \\
\hline At prescriber le & & $n=78$ & \\
\hline Prescriber inform & only & 47 & 60.26 \\
\hline Prescriber asked & information & 4 & 5.13 \\
\hline Intervention reco & nended, outcome unknown & 27 & 34.62 \\
\hline At patient/carer & & $\mathrm{n}=\mathbf{2 1 1}$ & \\
\hline Patient (medicati & counseling & 111 & 52.61 \\
\hline Written informati & orovided only & 21 & 9.95 \\
\hline Patient referred $t$ & rescriber & 62 & 29.38 \\
\hline Spoken to family & mber/caregiver & 17 & 8.06 \\
\hline At drug level & & $\mathrm{n}=\mathbf{1 7 0}$ & \\
\hline Drug changed & & 11 & 6.47 \\
\hline Dosage changeo & & 84 & 49.41 \\
\hline Formulation char & & 0 & 0.00 \\
\hline Instructions for $\mathrm{u}$ & changed & 49 & 28.82 \\
\hline Drug stopped & & 21 & 12.35 \\
\hline New drug startec & & 5 & 2.94 \\
\hline Side effect repor & to authorities & 0 & 0.00 \\
\hline Outcomes & *Outcomes ( $n=234)$ & Freq & $\%$ \\
\hline Not known & Outcome of intervention not known & 32 & 13.68 \\
\hline Solved & Problem totally solved & 112 & 47.86 \\
\hline Partially solved & Problem partially solved & 42 & 17.95 \\
\hline Not solved & Problem not solved, lack of cooperation of patient & 12 & 5.13 \\
\hline & Problem not solved, lack of cooperation of prescriber & 36 & 15.38 \\
\hline & Problem not solved, intervention not effective & 0 & 0.00 \\
\hline & No need or possibility to solve problem & 0 & 0.00 \\
\hline
\end{tabular}

${ }^{7}$ Interventions were far more than the DTPs identified because a particular DTP may need more than one interventions at the same level and other levels to get it resolved, therefore the results were analysed according to the levels of the intervention; * Outcomes of 234 DTPs identified and intervened

380 DTPs were identified by Nascimento et al [29] in a period of two years, and Root et al [30] identified 88 DTPs from 40 patients. The difference in the number of DTPs encountered is probably due to differences in research design in terms of patients type, hospital types, duration of the studies and nature of data collected.Our study showed that mean drug per patient was almost 3.0 which is moderate, despite the involvement of older population of patients in this study. This might be due the fact that most of the DTPs encountered in the hospital were not recorded or were even missed by pharmacists.

Inappropriate drug selection/dosing problem and drug interaction were the major sources of DTPs in this study. This result is consistent with a number of studies [25,29-33] on DTPs in which dosing and/or drug selection problems and drug interaction were identified among the major forms of DTPs encountered.

A high number of DTPs due to drug choice/selection and potential drug interactions was recorded in our study. This is similar to results obtained in a study conducted by Ismail et al [34] which showed $45 \%$ potential drug-drug interactions at pulmonology ward in a tertiary care hospital at Peshawar, Pakistan. Our results confirm that drug-drug interaction is a common drug therapy problem in both government and private hospitals. Khanet al [35] and Alagiriswami et al [36] also reported high incidence of drug selection problems.

The result of this study also revealed that the number of interventions was highest at patient/career level, followed by drug level and least at prescriber level. This is in agreement with the data from a 10-year study by Ramalho et al [28] where $80 \%$ of DTPs identified in Fairview's MTM programme were resolved at the drug or patient level without the direct involvement of physician(s).

The trend of recommendation approval found in this study is also similar to the results of Root et al [30] where $75 \%$ of the pharmacists' proposed interventions were approved. The lower rate of approval of proposed intervention obtained in the current study could be as a result of lack of collaboration between healthcare providers. 
Appreciable number of DTPs identified were totally resolved. Just like in many studies where pharmaceutical care interventions were instituded [28-30], DTPs were resolved, patients' conditions were improved and consequently the rate of encoutered DTPs in that setting was reduced. This is predicated in high acceptance of the intervention by the doctors. Pharmacists in this hospital should embrace this opportunity to reach out to patients who are greatly in need of their attention; no matter how busy they are, especially in this era of ever expanding role of a pharmacist.

The present study has several limitations and the results are interpreted in this light. The approach used to identify and classify DTPs was based on record reviews and explicit criteria of the applied guidelines. We could not account for information other than those in patients' records and those reported to us. Likewise, we focused on regularly scheduled medications rather than on as-needed drugs. Thus, our findings may be biased toward reporting more of the easily identifiable DTPs.

\section{CONCLUSION}

Drug therapy problems among the renal patients studied were high. Inappropriate drug selection and drug interactions were the commonest drug therapy problems. Pharmacists in Nigerian hospitals should always reach out to all patients to identify and resolve any drug-related problems associated with the patients' medications.

\section{DECLARATIONS}

\section{Conflict of Interest}

No conflict of interest associated with this work.

\section{Contribution of Authors}

The authors declare that this work was done by the authors named in this article and all liabilities pertaining to claims relating to the content of this article will be borne by them.

\section{Open Access}

This is an Open Access article that uses a funding model which does not charge readers or their institutions for access and distributed under the terms of the Creative Commons Attribution License (http://creativecommons.org/licenses/by 14.0) and the Budapest Open Access Initiative (http://www.budapestopenaccessinitiative.org/rea d), which permit unrestricted use, distribution, and reproduction in any medium, provided the original work is properly credited.

\section{REFERENCES}

1. Winterstein AG, Sauer BC, Hepler $C D$, Poole $C$. Preventable drug-related hospital admissions. Ann Pharmacother 2002; 36: 1238-1248. DOI: 10.1345/aph.1A225

2. Grymonpre RE, Mitenko PA, Sitar DS, Aoki FY, Montgomery PR. Drug-associated hospital admissions in older medical patients. J Am Geriatr Soc 1988; 36: 1092-1098. DOI: 10.1111/j.1532-5415.1988.tb04395.x

3. Col N, Fanale JE, Kronholm $P$. The role of medication noncompliance and adverse drug reactions in hospitalizations of the elderly. Arch Intern Med 1990; 150: 841-845. DOI: 10.1001./archinte.1990.003901 60093019

4. Kohn LT, Corrigan JM, Donaldson MS. To Err Is Human: Building a Safer Health System. National Academies Press: Washington, DC, 2000. Pp. 287. DOI: 10.17226/9728

5. Gurwitz JH, Field TS, Avorn J, McCormick D, Jain S, Eckler M, Benser M, Edmondson AC, Bates DW. Incidence and preventability of adverse drug events in nursing homes. Am J Med 2000; 109: 87-94. DOI: 10.1016/s0002-9343(00)00451-4

6. Gurwitz JH, Field TS, Harrold LR, et al. Incidence and preventability of adverse drug events among older persons in the ambulatory setting. JAMA 2003; 289: 1107-1116. DOI: 10.1001/jama.289.9.1107

7. Gandhi TK, Weingart SN, Borus J, Seger AC, Peterson J, Burdick E, Seger DL, Shu K, Federico F, Leape LL, Bates DW. Adverse drug events in ambulatory care. $N$ Engl J Med 2003; 348:1556-1564. DOI: 10.1056/nejmsa020703

8. Reddel H. Rational prescribing for ongoing management of asthma in adults. AustPrescr 2012; 35: 43-46. DOI: 10.18773/austprescr.2012.022

9. Akici $A$ and Oktay S. Rational pharmacotherapy and pharmacovigilance. Curr Drug Saf 2007; 2: 65-69. DOI: 10.2174/157488607779315408

10. Ali I, Khan AU, Zafar R. Pharmacotherapy analysis of patients admitted in medical ward: A case report. Can J App/Sci 2014; 3: 90-93.

11. Richardson TE, O'Reilly CL, Chen TF. Drug-related problems and the clinical role of pharmacists in inpatient mental health: An insight into practice in Australia. Int $\mathrm{J}$ Clin Pharm 2014; 36: 1077-1086. DOI: 10.1007/s11096014-9997-7

12. Patanwala $A E$, Sanders $A B$, Thomas MC, Acquisto NM, Weant KA, Baker SN. A prospective, multicenter study of pharmacist activities resulting in medication error interception in the emergency department. Ann Emerg Med 2012; 59: 369-373. DOI: 10.1016/j.annemerg med.2011.11.013

13. Rothschild JM., Churchill W, Erickson A, Munz K, Schuur $J D$, Salzberg $C A$, Lewinski $D$, Shane $R$, Aazami $R$, 
Patka $J$, et al. Medication errors recovered by emergency department pharmacists. Ann Emerg Med 2010; 55: 513-521. DOI: 10.1016/j.annemergmed. 2009.10.012

14. Vasileff HM, Whitten LE, Pink JA, Goldsworthy SJ, Angley MT. The effect on medication errors of pharmacists charting medication in an emergency department. Pharm World Sci 2009; 31: 373-379. DOI: 10.1007/s11096-008-9271-y

15. Franklin BD, Reynolds $M$, Shebl NA, Burnett $S$, Jacklin $A$. Prescribing errors in hospital inpatients: $A$ three-centre study of their prevalence, types and causes. Postgrad Med J 2011; 87: 739-745. DOI: 10.1136/pgmj. 2011.117879

16. Tully MP and Buchan IE. Prescribing errors during hospital inpatient care: Factors influencing identification by pharmacists. Pharm World Sci 2009; 31: 682-688. DOI: 10.1007/s11096-009-9332-x

17. Nash K, Hafeez A, Hou S. Hospital-acquired renal insufficiency. Am J Kidney Dis 2002; 39(5): 930-936. DOI: 10.1053/ajkd.2002.32766

18. Grabe DW, Low CL, Bailie GR, Eisele G. Evaluation of drug related problems in an outpatient hemodialysis unit and the impact of a clinical pharmacist. ClinNephrol 1997; 47(2): 117-121.

19. Harold J. Manley, Marcy L. McClaran, Debra K. Overbay, Marcia A. Wright, Gerald M. Reid, Walter L. Bender, Timothy K. Neufeld, Sudarshan Hebbar, Richard S. Muther. Factors associated with medication-related problems in ambulatory hemodialysis patients. Am J Kidney Dis 2003; 41(2): 386-393. DOI: 10.1053/ ajkd.2003.50048

20. Pharmaceutical Care Network Europe Foundation. PCNE Classification for Drug Related problems (revised 14-0110 vm) V6.2 2010.http://www.pcne.org/workinggroups/2/drug-related-problems (accessed 1 February 2015).

21. Kidney Disease: Improving Global Outcomes (KDIGO) CKD Work Group. KDIGO 2012 Clinical Practice Guideline for the Evaluation and Management of Chronic Kidney Disease.Kidney inter 2013; 3: 1-150. http://www.kdigo.org/clinical_practice_guidelings/pdf/CK D/KDIGO_2012_CKD_GL.pdf (accessed 12 January 2015)

22. University of Michigan Health System. Management of Chronic Kidney Disease Guideline, March 2014. http://www.med.umich.edu/1info/FHP/practiceguidelines /kidney/CKD.pdf (accessed 21 January 2015)

23. RxList: the internet drug index. http://www.rxlist.com/drug-interaction-checker.htm (accessed 12 July 2015)

24. Stella $M$, Giron $T$, Claesson $C$, Thorslund $M$, Oke $T$, Winblad B, Fastbom J. Drug Use Patterns in a very elderly population: a seven-year review. Clin Drug Invest 1999 17(5): 389-398. DOI: 10.2165/00044011199917050-00005
25. Rahmawati $F$, Pramantara DP, Rohmah W, Sulaiman SAS. Polypharmacy and unnecessary drug therapy on geriatric hospitalized patients in yogyakarta hospitals, Indonesia. Int J Pharm and Pharm Sci 2009; 1(1): 6-11.

26. High Authority for Health (HAS). Therapeutics for the management of chronic kidney disease patients. Paris, 2004.http://www.has-sante.fr/portail/upload/docs/ application/pdf/IRC_2006_recos.pdf. (accessed 14 August 2015)

27. Joseph T. Hanlon, Kenneth E. Schmader, Christine M. Ruby, Morris Weinberger. Suboptimal prescribing in older inpatients and outpatients. J Am GeriatrSoc2001; 49: 200-209. DOI: 10.1046/j.1532-5415.2001.49042.x

28. Ramalho de Oliveira $D$, Brummel AR, Miller $D B$. Medication therapy management: 10 years of experience in a large integrated health care system. $J$ Manag Care Pharm 2010 16(3): 185-195. DOI: 10.18553/jmcp.2010.16.3.185

29. Nascimento YA, Carvalho WS, Acurcio FA. Drug-related problems observed in a pharmaceutical care service, Belo Horizonte, Brazil. Braz J Pharm Sci2009 45(2): 321-330. DOI: 10.1590/s 1984-82502009000200018

30. Root R, Phelps P, Brummel A, Else C. Implementing a pharmacist-led medication management pilot to improve care transitions. Innovation in Pharmacy 2012; 3 No. 2. http://www.pubs.lib.umn.edu/innovations/vo/3/iss2/2/ (Accessed 23 September, 2015)

31. Odili VU, Egiebor BO, Oparah AC. Identification of Drug Therapy Problems in Patients with Diabetes Treated in a Secondary Care Facility in Benin City. Nig J Pharm Res 2011;9(1): 72-81.

32. Blix HS, Viktil KK, Reikvam S, Moger TA, Hjemaas BJ, Pretsch $P$, Tine Flindt, Vraalsen Elspeth $K$. Walseth The majority of hospitalised patients have drug-related problems: results from a prospective study in general hospitals. Eur J Clin Pharmacol 2004; 60(9): 651-658. DOI: 10.1007/s00228-004-0830-4

33. Suleiman IA, Eniojukan JF, Eze I. Evaluating pharmaceutical care documentation among pharmacists in Nigeria. West Afr J Pharm 2012; 23(1): 69 - 76.

34. Ismail $M$, lqbal $Z$, Khan MI, Javaid $A$, Arsalan $H$, Farhadullah $H$, Khan $F$, Khan $A Z$, Nasir $F$, Khan JA. Prevalence, types and predictors of potential drug-drug interactions in pulmonolgy ward of a tertiary care hospital. Afr J Pharm Pharmacol2011; 5: 1303-1309.

35. Khan A, Ali I, Zafar R, Khalil A. Identification of drugrelated problems and pharmacist's interventions in asthmatic patients at a private tertiary care facilityPakistan. Arch PharmaPract2015; 6: 33-37. DOI: 10.4103/2045-080x.155511

36. Alagiriswami B, Ramesh $M$, Parthasarathi $G$, Basavanagowdappa H. A study of clinical pharmacist initiated changes in drug therapy in a teaching hospital. Indian J Pharm Pract 2009; 2: 36-45. 